\title{
Simplifying complexity: genetically resculpting glycosphingolipid synthesis pathways in mice to reveal function
}

\author{
Maria Laura Allende • Richard L. Proia
}

Received: 3 September 2014 / Accepted: 3 October 2014 / Published online: 29 October 2014

(C) Springer Science+Business Media New York (outside the USA) 2014

\begin{abstract}
Glycosphingolipids (GSLs) are a group of plasmamembrane lipids notable for their extremely diverse glycan head groups. The metabolic pathways for GSLs, including the identity of the biosynthetic enzymes needed for synthesis of their glycans, are now well understood. Many of their cellular functions, which include plasma-membrane organization, regulation of cell signaling, endocytosis, and serving as binding sites for pathogens and endogenous receptors, have also been established. However, an understanding of their functions in vivo had been lagging. Studies employing genetic manipulations of the GSL synthesis pathways in mice have been used to systematically reduce the large numbers and complexity of GSL glycan structures, allowing the in vivo functions of GSLs to be revealed from analysis of the resulting phenotypes. Findings from these studies have produced a clearer picture of the role of GSLs in mammalian physiology, which is the topic of this review.
\end{abstract}

Keywords Glycosphingolipids · Glycosyltransferases · Gangliosides · Mouse models · Gene targeting

\section{Introduction}

Glycosphingolipids (GSLs) constitute the most structurally diverse subgroup of the sphingolipid family [1]. They contain a hydrophilic glycan head group, consisting of one or more oligosaccharide residues, and a hydrophobic ceramide anchor. The GSLs reside primarily in plasma membranes, with the ceramide anchor embedded in the lipid bilayer and the

M. L. Allende • R. L. Proia $(\bowtie)$

Genetics of Development and Disease Branch, National Institute of Diabetes and Digestive and Kidney Diseases, National Institutes of Health, Building 10, Room 9D-06; 10 Center DR MSC 1821, Bethesda, MD 20892-1821, USA

e-mail: proia@nih.gov oligosaccharide head group exposed to the extracellular environment.

Dedicated GSL synthesis is initiated by the transfer of either a glucose or a galactose moiety in $\beta$-linkage to the position 1 hydroxyl group of ceramide, resulting in the formation of glucosylceramide (GlcCer) or galactosylceramide (GalCer) (Fig. 1). The subsequent addition of galactose to GlcCer forms lactosylceramide (LacCer). LacCer serves as a hub in the pathway in which the substrate can be diverted into one of several pathways by the actions of distinct glycosyltransferases that lead to the formation of GSL subfamilies, with distinct core or root carbohydrate sequences, known as GSL series (Fig. 1). GalCer is also modified similarly subsequent to its synthesis, but the complexity the GalCer-based GSLs (gala series) is far less than that of the GlcCer-based GSLs.

When the oligosaccharide head groups of GSLs are modified by the addition of one or more sialic acids (usually $\alpha-2,3-$ or $\alpha$-2,8-linked $N$-acetylneuraminic acid), the GSLs produced are termed gangliosides [2] (Fig. 1). GSL head groups can also be modified by sulfate and are called sulfatides. All told, the number of GSLs with distinct oligosaccharide structures has been estimated to be greater than 400 [1].

Some of the mechanisms by which GSLs exert their functions at a cellular and molecular level have been well defined $[1,3-5]$. Their most basic function is as building blocks of the plasma membrane. In this case, GSLs, due to their ability to form liquid-ordered phases in membranes, can drive the formation of functionally and structurally discrete plasmamembrane domains $[3,6]$. GSLs, through their glycan head groups, can act as binding sites for pathogens and toxins [7] and, in a similar manner, for endogenous molecules, such as myelin-associated glycoprotein, to facilitate cell-to-cell interactions [8]. Through lateral interactions with membrane proteins, such as the insulin and epidermal growth factor receptors, GSLs can modulate the strength of receptor-mediated signaling pathways $[9,10]$. Finally, they can function 
Fig. 1 GSL synthesis pathways. Genes that have been targeted are in the rounded boxes. The major mouse phenotypes caused by genetic blocks in the GSL pathways are indicated in red text. For a description of the complete pathways, see Merrill [1]. Cer, ceramide; GalCer, galactosylceramide; $\mathrm{GlcCer}$, glucosylceramide; $\mathrm{LacCer}$, lactosylceramide; $\mathrm{NeuNAC}$, neuraminic acid

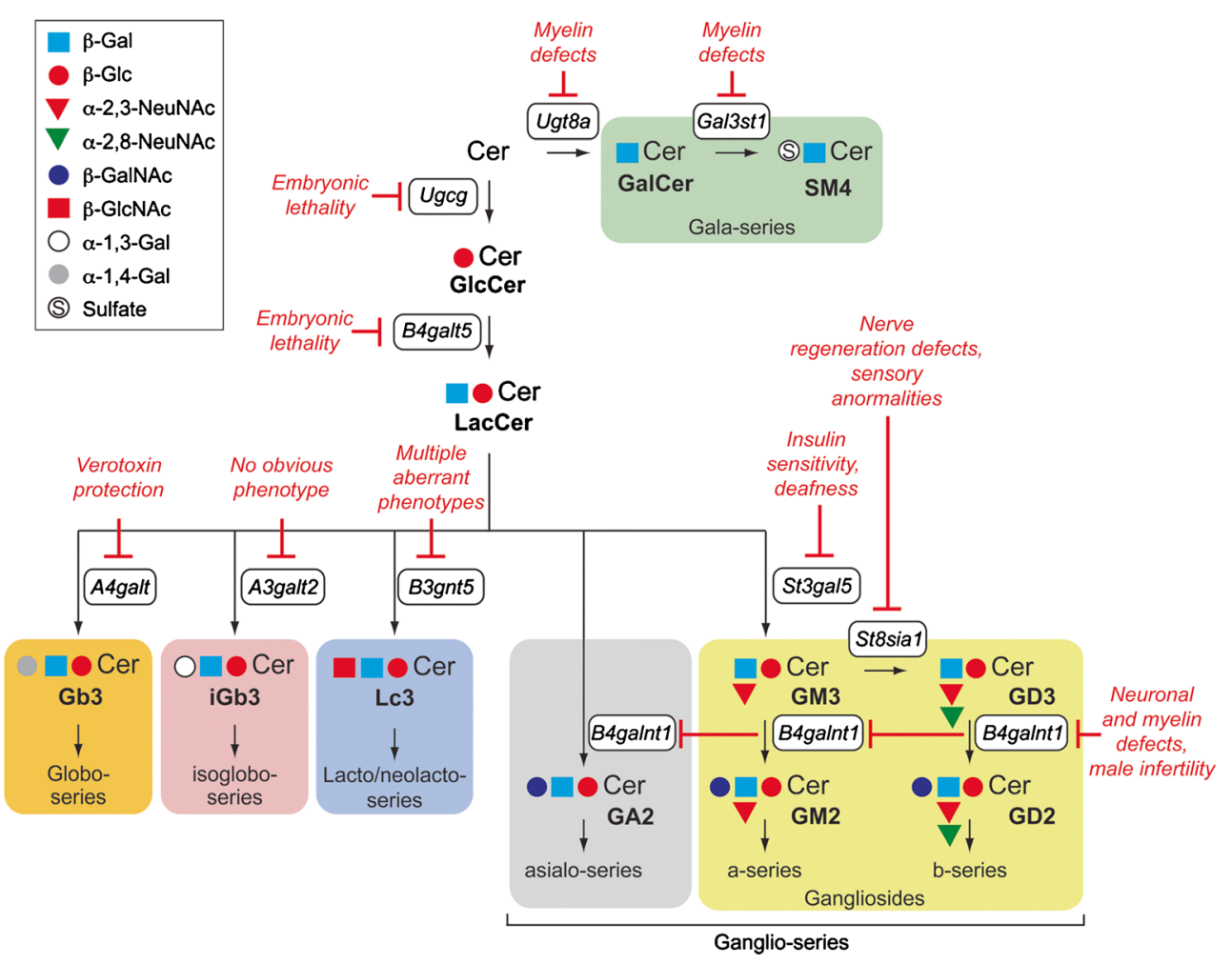

dynamically in the endocytic pathway by participating in the internalization of diverse cargoes [11].

This review focuses on GSL functions at a physiological level in mammals. A major challenge in this area has been to uncover their actions in the midst of the enormous structural variation of the glycan head groups that may be a source of the GSLs' functional diversity. This hurdle has been overcome by the systematic elimination of diverse GSL glycan structural groups in genetic deletion studies. Through the targeting of specific glycosyltransferases and other modifying enzymes, either singly or in combination and in a tissue-specific fashion - in effect simplifying the complexity of the GSLs - their in vivo functions have been elucidated from analysis of the resulting phenotypes.

\section{Global deletion of glucosylceramide-derived GSLs ( $\mathrm{Ugcg}$ knockout)}

UDP-glucose:ceramide glycosyltranferase (GlcCer synthase) is the rate-limiting enzyme for GlcCer-based GSL biosynthesis. It is encoded by the Ugcg gene in the mouse $[12,13]$. GlcCer synthase catalyzes the synthesis of GlcCer by the transfer of a glucose residue from UDP-glucose to ceramide. Once formed, GlcCer is modified by glycosyltransferases in the Golgi, ultimately giving rise to hundreds of more complex GSLs [1] (see Fig. 1).
Global deletion of the $U g c g$ gene in mice, which consequently eliminates all GlcCer-based GSLs, caused early embryonic lethality [14]. Ugcg knockout (KO) embryos developed until gastrulation at E6.5, forming the ectodermal, endodermal, and mesodermal layers, and with embryonic patterning. A day later, mutant embryos showed retarded growth and extensive apoptosis, primarily in the ectodermal layer, and were subsequently resorbed. These results are a vivid demonstration that GlcCer-based GSL synthesis is an absolute requirement for mammalian embryonic development [15].

\section{Pan nervous-system deletion of GlcCer GSLs}

GSLs, primarily in the form of gangliosides, are abundantly expressed in the nervous system, making up about $10 \%$ of the total lipids and suggesting a vital role during the formation of and/or function in these tissues $[5,16]$. In order to determine the importance of these lipids during the formation of a functional nervous system, two independently derived lines of mice lacking $U g c g$ in neuronal and glia cells were established by combining a floxed $\mathrm{Ugcg}$ allele and a Cre recombinase transgene under the control of the pan nervous system rat nestin promoter and enhancer (NesCre) [17, 18]. NesCre-Ugcg KO mice did not show evidence of embryonic lethality and appeared normal at birth. However, they developed neurologic 
abnormalities over time. The severity of the phenotypes in the two lines was different and appeared to be related to the level of residual $U g c g$ expression found in the respective NesCre-Ugcg KO brains. The mouse line produced by Jennemann et al. [18], in which the levels of $U g c g$ mRNA and gangliosides in brain were nearly completely eliminated, died by 3 weeks of age, and displayed very severe neurological symptoms, including ataxia, reduced axonal branching of neurons, and disturbed myelination of peripheral nerves. The line generated in the Proia laboratory [17] showed residual $U g c g$ expression, a significant, but incomplete reduction of ganglioside levels in the brain, as well as a longer life span. These mice also displayed abnormal gait, along with a progressive loss of Purkinje cells [18].

These reports show that GlcCer-based GSL synthesis is expendable for embryonic development of the nervous system, but is required for its proper development, stability, and function after birth.

\section{Neuronal-specific deletion of GlcCer-based GSLs}

The deletion of $U g c g$ specifically in neuronal cells was achieved by generating floxed $U g c g$ mice expressing the $\mathrm{Cre}$ recombinase gene under the L7 promoter only in Purkinje cells [19]. These mice, showed Purkinje cell degeneration at about 3-4 months of age, which was characterized by axon swelling and accumulation of axonal transport cargos prior to Purkinje cell loss. Significant abnormal myelination was present, as were detached paranodal junctions (the attachment sites of neuronal axons and oligodendrocytes), implying that the neuronally synthesized GSLs were critical for these axonalglial interactions.

In a separate study, $U g c g$ was deleted after birth using an inducible $\mathrm{Cre}$ recombinase (Cre-ERT2) under the control of the neuronal calcium/calmodulin-dependent kinase II $\alpha$ promoter (CamK). In these mice, expression of the Ugcg gene was deleted from the neurons of the forebrain, including the hypothalamic nuclei, which are involved in energy homeostasis regulation. CamKCre-ERT2-Ugcg KO mice showed progressive body-weight gain, hypometabolism, and hypothermia. This phenotype could be reversed by virus-mediated expression of $U g c g$ in the arcuate nucleus (Arc) of the hypothalamus, a key regulator of feeding and metabolism. Leptin signaling, which is essential for metabolic homeostasis, was impaired in Arc neurons from the CamKCre-ERT2-Ugcg KO mice. The basis for the impaired leptin responsiveness in the Arc neurons appeared to be due to a lack of GlcCer-based gangliosides, which normally directly associate with the leptin receptor on the plasma membrane and promote leptin responsiveness [20].

\section{Oligodendrocyte-specific deletion of GlcCer-based GSLs}

Ugcg was deleted specifically in oligodendrocytes by crossing floxed $U g c g$ mice with a line expressing $C r e$ recombinase under the control of the myelin-associated enzyme $2^{\prime}, 3^{\prime}$ cyclic nucleotide 3' phosphodiesterase (CnpCre) [21]. The resulting oligodendrocyte-specific CnpCre-Ugcg KO mice did not show any myelin abnormalities, indicating that oligodendrocyte GlcCer-derived GSLs, unlike those produced by neuronal cells, are not essential for myelin structure and stabilization.

\section{Keratinocyte-specific deletion of Glc-Cer based GSLs}

Keratinocytes produce large amounts of GSLs, mainly GlcCer, accounting for almost $4 \%$ of the total lipid content in the epidermis, which is packed into lamellar bodies and delivered to the stratum corneum for further processing to generate ceramide [22, 23]. Floxed Ugcg mice were crossed with a keratin K14 promoter-driven $\mathrm{Cre}$ line to produce mice lacking $U g c g$ expression in keratinocytes $(\mathrm{K} 14 \mathrm{Cre}-\mathrm{Ugcg} \mathrm{KO}$ mice) [24]. K14Cre-Ugcg KO pups showed profound desquamation and epidermal dehydration and died at about 4 days of age. Their skin showed broadened epidermal layers, abnormal lamellar bodies, keratinocyte apoptosis, and inflammation. When epidermal deletion was induced after birth using a tamoxifen-inducible (TAM) K14Cre transgene to bypass the early lethality, TAM-K14Cre-Ugcg KO mice showed epidermal abnormalities similar to the $\mathrm{K} 14 \mathrm{Cre}-\mathrm{Ugcg} \mathrm{KO}$ mice [25]. These studies supported the conclusion that $U g c g$ expression is essential for the formation of a functional epidermal permeability barrier through the generation of GlcCer, a precursor for the formation of ceramide in the skin.

\section{Liver-specific deletion of Glc-Cer based GSLs}

Liver is a central site controlling sphingolipid metabolism [26]. A liver-specific knockout of Ugcg was generated by crossing floxed $\mathrm{Ugcg}$ mice with mice expressing Cre recombinase under the control of the albumin promoter (AlbCre-Ugcg mice) [27]. The mice had greatly reduced GSL levels in liver and plasma, pinpointing liver as the major source of plasma GSLs. No other phenotype was detected in the AlbCre-Ugcg mice, even after challenge with a high-fat diet, arguing against a vital role of hepatic GlcCer synthesis in glucose control, liver steatosis, or cholesterol metabolism.

\section{Enterocyte-specific deletion of Glc-Cer based GSLs}

GSLs are highly concentrated in the columnar epithelial cells that form the villi in the intestine, known as enterocytes. 
Enterocyte-specific $U g c g$-deficient mice were generated by crossing floxed $\mathrm{Ugcg}$ mice with mice expressing Cre recombinase under the control of the villin promoter induced either in the embryo (using VilCre-expressing mice) or during adult life (using VilCre-ERT2-expressing mice) [28]. GlcCerderived GSLs were profoundly absent in the intestines of the VilCre-Ugcg pups. Although undistinguishable from control littermates at birth, VilCre-Ugcg pups did not gain weight and died by postnatal day 8 . VilCre-Ugcg pups showed normal polarization of the enterocytes, but had abnormal mucosal villi, decreased fat deposits, and a severe decrease in the ability of enterocytes to uptake lipid. Inducible VilCre-ERT2$\mathrm{Ugcg}$ mice showed an almost complete absence of intestinal GSLs 4 days after deletion induction, which was concomitant with significant structural alterations in the villous epithelia. These mice also had decreased body weight and reduced lipid absorption by the enterocytes. These findings demonstrate that GlcCer-derived GSLs are necessary for proper intestinal function.

\section{Deletion of lactosylceramide-based GSLs: B4galt5 KO}

LacCer is synthesized in the Golgi lumen by LacCer synthase ( $\beta$-1,4-galactosyltransferase 5) via the transfer of galactose from UDP-galactose to GlcCer. B4galt5 null mice were generated by conventional gene targeting [29] and through a large-scale gene-trap project [30]. Both gene targeting strategies led to lethality in utero. The $B 4$ galt $5^{-1-}$ embryos appeared normal until E6.5, showed retarded growth by E7.5, and died around E10.5. B4galt $5^{-/-}$embryos showed bleeding in the extra-embryonic tissues at E7.5 [29]. The early lethality of the B $_{\text {galt }} 5^{-/-}$embryos could be rescued by wild-type extra-embryonic tissues; however, these embryos did not develop past E18.5, indicating that $B 4$ galt 5 has a direct role in later embryonic development within the embryo proper [29].

\section{Deletion of ganglio-series GSLs: B4galnt1 KO}

GM 2 / G D 2 s ynthase $(\beta-1,4-N-$ a c e ty $1-$ galactosaminyltransferase), which is encoded by B4galnt1, transfers $N$-acetylgalactosamine to LacCer to initiate the synthesis of ganglio-series GSLs, including the sialic acidcontaining gangliosides (Fig. 1) [31]. The genetic deletion of B4galnt1 resulted in mice lacking the normal complement of complex gangliosides and instead expressing predominantly GM3 and GD3 (Fig. 1) [32, 33]. Despite the drastic change in the ganglioside composition, B4galnt $1^{-/-}$mice unexpectedly underwent largely normal brain development.

However, B4galnt1 $1^{-/}$mice were found to display decreased myelination of central axons, as well as demyelination of peripheral nerves [33]. As a consequence, axon degeneration occurred within the central nervous system, leading to impaired motor function [33, 34]. Nodes of Ranvier showed abnormal structures in $B 4$ galnt $1^{-/-}$mice, causing defects in conduction velocity of the motor nerves [33]. One of the functions of gangliosides within the axonal membrane is as ligands for MAG displayed on oligodendrocytes to promote axon-glia interactions [35]. Indeed, B4Galnt1 -/mice showed a decrease in MAG expression in the brain [33] and MAG deficient mice displayed a similar phenotype as B4Galnt1 -1- mice [35]. These findings suggest that the lack of complex ganglioside-MAG interactions was a cause of the B4Galnt1 null phenotype and demonstrate an essential role in myelin stabilization. Another independently generated B4galnt $1^{-1-}$ mouse line showed subtle defects in the nervous system, with a slight reduction in the neural conduction velocity and a defect in cognitive performance [36]. These findings indicate an essential role for gangliosides in myelin stabilization and for proper neuronal function.

The discovery that $B 4$ galnt $^{-/-}$male mice are infertile revealed an important function of complex gangliosides in spermatogenesis $[32,33,37]$. The absence in the B $_{\text {galnt }} 1^{-/}$ male mice of a novel class of fucosylated, polyunsaturated GSLs with highly elongated fatty acids typically present in male germ cells was linked to their infertility [38].

\section{Deletion of a-series gangliosides: St3gal5 KO}

GM3 synthase (CMP-sialic acid:lactosylceramide $\alpha-2,3-$ sialyltransferase) is encoded by St3gal5. The enzyme transfers sialic acid to LacCer to produce GM3, the simplest of the sialic acid-containing GlcCer-based gangliosides and a precursor for complex gangliosides [2].

St3gal5-deficient mice had normal life span [39]. Analysis of their ganglioside content demonstrated the absence of GM3 and all GM3-derived gangliosides from the a- and b- series (Fig. 1), which are the major gangliosides in the brain [2].

GM3 synthase deletion increased insulin sensitivity; that is, St3 gal5 $5^{-1-}$ mice had enhanced phosphorylation of the insulin receptor in skeletal muscle after insulin binding, and better responses in glucose- and insulin-tolerance tests. Accordingly, they were also protected from insulin resistance development after a high-fat diet regimen [39].

Diabetic diet-induced obese St3gal5 ${ }^{-1-}$ mice were also found to be protected from a wound-healing defect. Wound healing generally involves proliferation and migration of keratinocytes, which are both mediated by the insulin receptor and insulin growth factor-1 receptor. Because diabetic obese St3gal5 $5^{-/}$mice indeed had activated insulin receptor and insulin growth factor-1 receptor signaling, particularly in the presence of high glucose, the wound-healing defects observed in wild-type diabetic obese mice were obviated [40]. 
An independently generated line of St3 all $^{-1-}$ mice exhibited complete hearing loss [41]. The St3gal5 ${ }^{-/}$mice showed degeneration and disappearance of the organ of Corti, which is the hearing sensor in the cochlea. These results suggest that GM3 synthesis is essential for the early maturation of the cochlea and that it is important in development of the auditory system.

\section{Deletion of b-series gangliosides: St8sia1 KO}

GD3, the precursor of the di-sialo b-series gangliosides (Fig. 1), is generated by the addition of sialic acid to GM3 by GD3 synthase (CMP-sialic acid: GM3 $\alpha-2,8-$ sialyltransferase), encoded by the St 8 sial gene. Despite the absence of the normally prominent $b$-series gangliosides in the brain, the deletion of the St8sial gene did not cause apparent developmental abnormalities in the nervous system $[42,43]$. Adult St8sial ${ }^{-/}$mice were found to be viable and grossly normal.

A second independently derived line of St8sial ${ }^{-1-}$ mice exhibited reduced regeneration capacity of the hypoglossal nerve, showing fewer surviving neurons after resection of the nerve [42]. In addition, St8sial ${ }^{-/-}$mice displayed increased sensory responses to thermal and mechanical stimuli and decreased response to subcutaneous formalin injection, which is a measure of clinical pain, suggesting GD3-based gangliosides mediate transmission of pain and might be important in the sensory system [44].

\section{“GM3-only" mice: St8sia1/B4galnt1 double knockout}

St8sia1/B4galnt1 double knockout (DKO) mice were generated by crossing animals carrying the St8sial and B4galnt1 null alleles [43]. Homozygous DKO mice were viable and expressed only GM3 as a GlcCer-based ganglioside in their brains. Strikingly, these DKO mice were extremely susceptible to sound-induced lethal seizures, and most died by 3 months of age [43]. A separate DKO line did not display any seizure-related phenotype, although these mice had decreased weight, motor dysfunction, low fear stress, and reduced sensory responses due to peripheral nerve degeneration [45]. These DKO mice also acquired severe skin lesions, possibly caused by the reduced sensory function [46]. These findings show that complex ganglioside expression is essential to maintain the normal function of the central and peripheral nervous systems, and that these functions of complex ganglioside structures cannot be replaced by the expression of the simple ganglioside GM3.
“Ganglioside-less" mice: St3gal5/B4galnt1 DKO

Phenotypes seen in B4galnt1 ${ }^{-/-}$or St8sia1/B4galnt1 DKO mice demonstrated that expression of even simple gangliosides such as GM3 and GD3 were sufficient for the development of a functioning nervous system, although with some defects. To answer if gangliosides were truly essential for nervous-system development, the elimination of all GlcCerbased gangliosides was achieved by crossing mice carrying null mutations in the St3gal5 and B4galnt1 genes (Fig. 1) to create St3gal5/B4galnt1 DKO mice. These DKO mice were initially viable but soon developed hindlimb weakness, tremors, and ataxia; most died within 3 months of birth [47]. As expected, and in accordance with the proposed biosynthetic pathway, these DKO mice were unable to synthesize any gangliosides of the ganglio-series and instead accumulated LacCer. DKO mice showed severe neurodegenerative symptoms, including a smaller brain and prominent areas of vacuolization in the spinal cord and brain white matter. Myelinated axons were degenerated in these mice, and showed abnormalities of paranodal junctions at the nodes of Ranvier, which suggests impairment of the axon-glia interactions. These findings indicate that GlcCer-based gangliosides are not required for early neural differentiation or morphogenesis of the brain, but are critical for promoting the formation or stabilization of functional axon-glia interactions. The absence of gangliosides ultimately leads to axonal degeneration.

\section{Deletion of the globo-series of GSLs: A4galt KO}

Gb3 synthase ( $\alpha$-1,4-galactosyltransferase), which is encoded by the A4galt gene, is responsible for the synthesis of $\mathrm{Gb} 3$ (Gal $\alpha 1-4 \mathrm{Gal} \beta 1-4 \mathrm{Glc} \beta 1 \mathrm{Cer}$ ) by the addition of an $\alpha-1,4-$ linked galactose to LacCer, initiating the production of the globo-series of GSLs. A4galt ${ }^{-/}$mice were deficient in Gb3 and other globo-series GSLs [48]. These KO mice appeared normal and lacked any obvious phenotype. Gb3 has been reported to be a ligand for the bacterial endotoxins Shigalike and verotoxins, which are associated with hemorrhagic colitis and hemolytic uremic syndrome. Accordingly, A4galt ${ }^{-1}$ mice were found to be protected from the effect of these toxins, clearly demonstrating that globo-series GSLs are endogenous ligands for these toxins [48].

\section{Deletion of the isoglobo-series of GSLs: A3galt2 KO}

iGb3 synthase ( $\alpha$-1,3-galactosyltransferase), which is encoded by the A3galt 2 gene, initiates the formation of the isoglobo-series of GSLs with the synthesis of $\mathrm{iGb} 3$ (Gal $\alpha 1-$ $3 \mathrm{Gal} \beta 1-4 \mathrm{Glc} \beta 1 \mathrm{Cer})$ from LacCer by the addition of an $\alpha$ 1,3-linked galactose (Fig. 1). Deletion of the A3galt2 gene 
eliminated iGb3 and the other isoglobo-series GSLs derived from iGb3 [49]. Similar to the globo-series null mice, A3galt $2^{-/}$mice did not display any obvious phenotype. Although iGb3 was thought to be an endogenous ligand for the invariant $\mathrm{V} \alpha 14$-expressing natural killer $\mathrm{T}$ (NKT) cells, thereby regulating their development in thymus [50], A3galt ${ }^{-/-}$ mice showed normal NKT numbers and function [49]. This result suggests that this GSL species may not be a relevant ligand for thymic NKT cells in vivo.

\section{Deletion of the lacto/neolacto-series of GSLs: B3gnt5 KO}

Lc3 synthase ( $\beta-1,3-N$-acetylglucosaminyltransferases 5$)$, which is encoded by B3gnt5, produces Lc3 (GlcNAc $\beta 1-$ $3 \mathrm{Gal} \beta 1-4 \mathrm{Glc} \beta 1 \mathrm{Cer})$, initiating the lacto/neolacto-series of GSLs (Fig. 1), with the transfer of N-acetylglucosamine to LacCer. Three independent groups have reported targeting the $B 3 g n t 5$ gene in mice, with different outcomes. Genetic deletion of the B3gnt5 gene in mice by Biellmann et al. [51] caused embryonic lethality at the preimplantation stage, possibly due to defects in cell-cell adhesion that contribute to embryo compaction and implantation. The line generated by Togayachi et al. produced viable $B 3 g n t 5^{-/-}$mice that showed a defect in B-cell signaling due to abnormal raft formation [52]. Kuan et al. [53] developed B3gnt $5^{-/}$mice by two different strategies. They reported that $B 3 g n t 5^{-1-}$ mice showed splenomegaly and enlarged lymph nodes, and had shorter, variable life spans. They also had lower B-cell numbers, exhibited hair loss, were obese, and had reproductive defects. The reasons for the discrepancies among the phenotypes of the $B 3 g n t 5^{-/-}$mouse lines in the three reports are not apparent.

\section{Deletion of GalCer-based GSLs: Ugt8a KO}

Galactosylceramide synthase (UDP-galactose:ceramide galactosyltransferase), encoded by the Ugt8a gene, catalyzes the formation of GalCer by the attachment of a galactose residue to the ceramide backbone (Fig. 1) [13, 54]. GalCer and its sulfated derivative, GalCer-sulfate or SM4 (Fig. 1), are greatly enriched in the myelin sheath that covers axons, representing nearly $30 \%$ of the total lipid [55]. Two independent groups generated Ugt $8 a$-deficient mouse lines through conventional targeting of the Ugt8a gene [55, 56]. Homozygous $U g t 8 a^{-/-}$mice were initially viable, but were small and had shortened life spans. They also exhibited tremors, loss of locomotor activity, and disruption of nerve conduction. Surprisingly, $U g t 8 a^{-/-}$mice were able to form myelin sheaths lacking GalCer and its derivative SM4, but instead containing GlcCer, a GSL not normally abundant in myelin. The myelin structure of the $U g t 8 a^{-/-}$mice initially appeared normal, except for slightly thinner sheaths in some areas of the spinal cord. Later, the myelin became unstable and degenerated. Together, these studies demonstrated that GalCer synthesis is needed for long-term maintenance of the structure and function of the myelin.

Interestingly, restoration of oligodendrocyte Ugt8a expression was able to correct the aberrant phenotype in $U g t 8 a^{-/}$ mice, including normalizing life span, behavior, and myelin structure [57]. These results indicate that the loss of Ugt8a in oligodendrocytes was responsible for the myelin defects and altered behavior described for $U g t 8 a^{-/-}$mice.

\section{Deletion of sulfated GalCer: Gal3st1 KO}

Gal3st1 encodes for the glycolipid-specific GalCer sulfotransferase [58], which adds a sulfate group to GalCer to form SM4 which is incorporated into myelin (Fig. 1) [59-61]. To determine the role of sulfated GSL in vivo, mice with a deletion of Gal3stl were generated [62]. Gal3st1 ${ }^{-/}$ mice were normal at birth, but as they aged they developed neurological symptoms (exhibiting as weakness of the hindlimbs, tremors, and progressive ataxia) However, these mice were able to survive for more than 1 year. These mice lacked SM4, but still expressed GalCer in the brain [62]. Their axons were myelinated, but the myelin showed vacuolation, and exhibited defective paranodal junctions and abnormal ionchannel localization along the axon membrane [62-65]. These results demonstrate the important role of sulfated GalCer in the formation interactions between axons and glia.

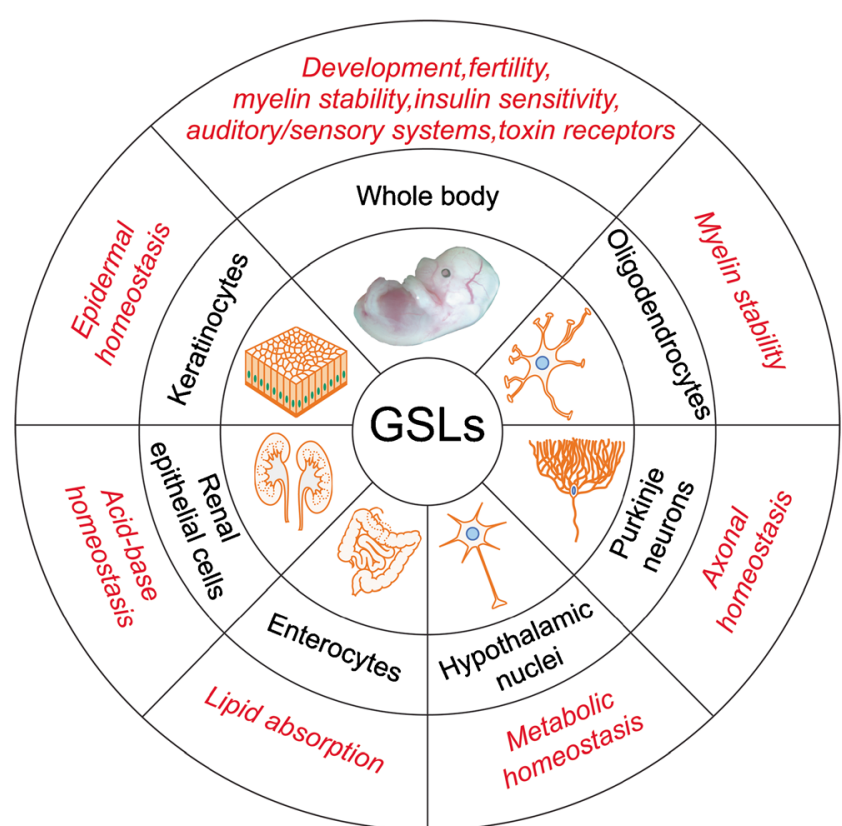

Fig. 2 In vivo GSL functions revealed by whole body and conditional gene deletion studies in mice 
Sulfated GSLs are highly enriched in the kidney, especially at the distal nephron segments and in the renal medulla [61, $66,67]$. To determine the role of sulfated GSLs specifically in kidney, Gal3st1 was deleted via renal epithelia-specific genetic disruption either individually to eliminate sulfated GSLs, or in combination with Ugcg to further remove possible compensatory anionic GlcCer-based GSLs, Mice carrying floxed Gal3st1 and Ugcg alleles were crossed with mice expressing the Cre recombinase gene under the control of the tubular epithelial cell-specific paired box gene 8 promoter (Pax8Cre) [68]. Kidneys from single (KO) and double KO (DKO) mice lacked the predicted sulfated GSL species in the kidney and showed generally normal kidney morphology. However, the Pax8Cre-Gal3st1 KO and Pax8Cre-Gal3st1/ Ugcg DKO mice both showed significantly lower $\mathrm{pH}$ and less ammonium excretion in the urine. When fed an acidic diet, the Gal3st1 ${ }^{-1-}$ mice exhibited decreased ammonium accumulation in the papilla, and chronic hyperchloremic acidosis. The results are consistent with the notion that sulfated GSLs in the kidney act as counterions of interstitial $\mathrm{NH}_{4}^{+}$, allowing its accumulation in the kidney papilla and enabling sufficient renal excretion of protons to maintain a proper blood $\mathrm{pH}$ [68]. The results show that sulfated GSLs are critical for physiologic acid-base homeostasis.

\section{Conclusions and perspectives}

During the period of time since the description of the first knockout mice targeting enzymes in the GSL synthesis pathway in 1996 [32, 55], we have seen a striking increase in our understanding of the roles of GSLs in physiology (Fig. 2). We have learned that they are not only fundamentally important for embryonic development, but also have key tissue-specific functions, including formation of the skin permeability barrier, acid handling in the kidney for maintenance of acid-base homeostasis, and key nervous-system functions (including in neuron-glial interaction to maintain myelin stability and neuronal control of appetite). It is likely that we have only scratched the surface of GSL functions, given the existence of hundreds of different GSL structures and that we only understand the function of a relatively very few. Furthermore, our knowledge of how GSLs act in human disease is only in its infancy. While lysosomal storage diseases in which GSL degradation pathways are disrupted have been known for many years [69], only recently have genetic diseases involving the GSL synthesis pathways been described [70-73]. A new challenge is to build on current insights into normal GSL functions (Fig. 2) to understand how GSLs play a role in the pathogenesis of other disorders. In this vein, significant progress is already being made in a number of human diseases [74-76]. These insights will eventually lead to therapeutics aimed at targeting specific GSL pathways for the treatment of these disorders.

Acknowledgments This work was supported by the Intramural Research Program of the National Institutes of Health, National Institute of Diabetes and Digestive and Kidney Diseases.

Conflict of interest The authors declare that they are free from conflict of interest.

\section{References}

1. Merrill Jr., A.H.: Sphingolipid and glycosphingolipid metabolic pathways in the era of sphingolipidomics. Chem Rev 111(10), 6387-6422 (2011). doi:10.1021/cr2002917

2. Kolter, T., Proia, R.L., Sandhoff, K.: Combinatorial ganglioside biosynthesis. J Biol Chem 277(29), 25859-25862 (2002). doi:10. 1074/jbc.R200001200

3. Cantu, L., Del Favero, E., Sonnino, S., Prinetti, A.: Gangliosides and the multiscale modulation of membrane structure. Chem Phys Lipids 164(8), 796-810 (2011). doi:10.1016/j.chemphyslip.2011.09.005

4. D'Angelo, G., Capasso, S., Sticco, L., Russo, D.: Glycosphingolipids: synthesis and functions. FEBS J 280(24), 6338-6353 (2013). doi:10.1111/febs.12559

5. Yu, R.K., Tsai, Y.T., Ariga, T.: Functional roles of gangliosides in neurodevelopment: an overview of recent advances. Neurochem Res 37(6), 1230-1244 (2012). doi:10.1007/s11064-012-0744-y

6. Sonnino, S., Mauri, L., Chigorno, V., Prinetti, A.: Gangliosides as components of lipid membrane domains. Glycobiology 17(1), 1R13R (2007). doi:10.1093/glycob/cw1052

7. Schengrund, C.L.: "Multivalent" saccharides: development of new approaches for inhibiting the effects of glycosphingolipid-binding pathogens. Biochem Pharmacol 65(5), 699-707 (2003)

8. Schnaar, R.L.: Brain gangliosides in axon-myelin stability and axon regeneration. FEBS Lett 584(9), 1741-1747 (2010). doi:10.1016/j. febslet.2009.10.011

9. Yoon, S.J., Nakayama, K., Hikita, T., Handa, K., Hakomori, S.I.: Epidermal growth factor receptor tyrosine kinase is modulated by GM3 interaction with N-linked GlcNAc termini of the receptor. Proc Natl Acad Sci U S A 103(50), 18987-18991 (2006). doi:10.1073/ pnas.0609281103

10. Inokuchi, J.: GM3 and diabetes. Glycoconj J 31(3), 193-197 (2014). doi:10.1007/s10719-013-9516-4

11. Lakshminarayan, R., Wunder, C., Becken, U., Howes, M.T., Benzing, C., Arumugam, S., Sales, S., Ariotti, N., Chambon, V., Lamaze, C., Loew, D., Shevchenko, A., Gaus, K., Parton, R.G., Johannes, L.: Galectin-3 drives glycosphingolipid-dependent biogenesis of clathrin-independent carriers. Nat Cell Biol 16(6), 595606 (2014). doi:10.1038/ncb2970

12. Ichikawa, S., Ozawa, K., Hirabayashi, Y.: Molecular cloning and expression of mouse ceramide glucosyltransferase. Biochem Mol Biol Int 44(6), 1193-1202 (1998)

13. Ichikawa, S., Sakiyama, H., Suzuki, G., Hidari, K.I., Hirabayashi, Y.: Expression cloning of a cDNA for human ceramide glucosyltransferase that catalyzes the first glycosylation step of glycosphingolipid synthesis. Proc Natl Acad Sci U S A 93(10), 4638-4643 (1996)

14. Yamashita, T., Wada, R., Proia, R.L.: Early developmental expression of the gene encoding glucosylceramide synthase, the enzyme controlling the first committed step of glycosphingolipid synthesis. Biochim Biophys Acta 1573(3), 236-240 (2002)

15. Yamashita, T., Wada, R., Sasaki, T., Deng, C., Bierfreund, U., Sandhoff, K., Proia, R.L.: A vital role for glycosphingolipid synthesis 
during development and differentiation. Proc Natl Acad Sci U S A 96(16), 9142-9147 (1999)

16. Kolter, T.: A view on sphingolipids and disease. Chem Phys Lipids 164(6), 590-606 (2011). doi:10.1016/j.chemphyslip.2011.04.013

17. Yamashita, T., Allende, M.L., Kalkofen, D.N., Werth, N., Sandhoff, K., Proia, R.L.: Conditional LoxP-flanked glucosylceramide synthase allele controlling glycosphingolipid synthesis. Genesis 43(4), 175-180 (2005). doi:10.1002/gene.20167

18. Jennemann, R., Sandhoff, R., Wang, S., Kiss, E., Gretz, N., Zuliani, C., Martin-Villalba, A., Jager, R., Schorle, H., Kenzelmann, M., Bonrouhi, M., Wiegandt, H., Grone, H.J.: Cell-specific deletion of glucosylceramide synthase in brain leads to severe neural defects after birth. Proc Natl Acad Sci U S A 102(35), 12459-12464 (2005). doi:10.1073/pnas.0500893102

19. Watanabe, S., Endo, S., Oshima, E., Hoshi, T., Higashi, H., Yamada, K., Tohyama, K., Yamashita, T., Hirabayashi, Y.: Glycosphingolipid synthesis in cerebellar Purkinje neurons: roles in myelin formation and axonal homeostasis. Glia 58(10), 1197-1207 (2010). doi:10. 1002/glia.20999

20. Nordstrom, V., Willershauser, M., Herzer, S., Rozman, J., von Bohlen Und Halbach, O., Meldner, S., Rothermel, U., Kaden, S., Roth, F.C., Waldeck, C., Gretz, N., de Angelis, M.H., Draguhn, A., Klingenspor, M., Grone, H.J., Jennemann, R.: Neuronal expression of glucosylceramide synthase in central nervous system regulates body weight and energy homeostasis. PLoS Biol 11(3), e1001506 (2013)

21. Saadat, L., Dupree, J.L., Kilkus, J., Han, X., Traka, M., Proia, R.L., Dawson, G., Popko, B.: Absence of oligodendroglial glucosylceramide synthesis does not result in CNS myelin abnormalities or alter the dysmyelinating phenotype of CGT-deficient mice. Glia 58(4), 391-398 (2010). doi:10.1002/glia.20930

22. Holleran, W.M., Takagi, Y., Uchida, Y.: Epidermal sphingolipids: metabolism, function, and roles in skin disorders. FEBS Lett 580(23), 5456-5466 (2006). doi:10.1016/j.febslet.2006.08.039

23. Rabionet, M., Gorgas, K., Sandhoff, R.: Ceramide synthesis in the epidermis. Biochim Biophys Acta 1841(3), 422-434 (2014). doi:10. 1016/j.bbalip.2013.08.011

24. Jennemann, R., Sandhoff, R., Langbein, L., Kaden, S., Rothermel, U., Gallala, H., Sandhoff, K., Wiegandt, H., Grone, H.J.: Integrity and barrier function of the epidermis critically depend on glucosylceramide synthesis. J Biol Chem 282(5), 3083-3094 (2007). doi:10.1074/jbc.M610304200

25. Amen, N., Mathow, D., Rabionet, M., Sandhoff, R., Langbein, L., Gretz, N., Jackel, C., Grone, H.J., Jennemann, R.: Differentiation of epidermal keratinocytes is dependent on glucosylceramide:ceramide processing. Hum Mol Genet 22(20), 4164-4179 (2013). doi:10. 1093/hmg/ddt264

26. Li, Z., Li, Y., Chakraborty, M., Fan, Y., Bui, H.H., Peake, D.A., Kuo, M.S., Xiao, X., Cao, G., Jiang, X.C.: Liver-specific deficiency of serine palmitoyltransferase subunit 2 decreases plasma sphingomyelin and increases apolipoprotein E levels. J Biol Chem 284(39), 27010-27019 (2009). doi:10.1074/jbc.M109.042028

27. Jennemann, R., Rothermel, U., Wang, S., Sandhoff, R., Kaden, S., Out, R., van Berkel, T.J., Aerts, J.M., Ghauharali, K., Sticht, C., Grone, H.J.: Hepatic glycosphingolipid deficiency and liver function in mice. Hepatology 51(5), 1799-1809 (2010). doi:10.1002/hep. 23545

28. Jennemann, R., Kaden, S., Sandhoff, R., Nordstrom, V., Wang, S., Volz, M., Robine, S., Amen, N., Rothermel, U., Wiegandt, H., Grone, H.J.: Glycosphingolipids are essential for intestinal endocytic function. J Biol Chem 287(39), 32598-32616 (2012). doi:10.1074/jbc. M112.371005

29. Nishie, T., Hikimochi, Y., Zama, K., Fukusumi, Y., Ito, M., Yokoyama, H., Naruse, C., Asano, M.: Beta4-galactosyltransferase5 is a lactosylceramide synthase essential for mouse extra-embryonic development. Glycobiology 20(10), 1311-1322 (2010). doi:10. 1093/glycob/cwq098
30. Kumagai, T., Tanaka, M., Yokoyama, M., Sato, T., Shinkai, T., Furukawa, K.: Early lethality of beta-1,4-galactosyltransferase Vmutant mice by growth retardation. Biochem Biophys Res Commun 379(2), 456-459 (2009). doi:10.1016/j.bbrc.2008.12.078

31. Lutz, M.S., Jaskiewicz, E., Darling, D.S., Furukawa, K., Young Jr., W.W.: Cloned beta 1,4 N-acetylgalactosaminyltransferase synthesizes GA2 as well as gangliosides GM2 and GD2. GM3 synthesis has priority over GA2 synthesis for utilization of lactosylceramide substrate in vivo. J Biol Chem 269(46), 29227-29231 (1994)

32. Takamiya, K., Yamamoto, A., Furukawa, K., Yamashiro, S., Shin, M., Okada, M., Fukumoto, S., Haraguchi, M., Takeda, N., Fujimura, K., Sakae, M., Kishikawa, M., Shiku, H., Aizawa, S.: Mice with disrupted GM2/GD2 synthase gene lack complex gangliosides but exhibit only subtle defects in their nervous system. Proc Natl Acad Sci U S A 93(20), 10662-10667 (1996)

33. Sheikh, K.A., Sun, J., Liu, Y., Kawai, H., Crawford, T.O., Proia, R.L., Griffin, J.W., Schnaar, R.L.: Mice lacking complex gangliosides develop Wallerian degeneration and myelination defects. Proc Natl Acad Sci U S A 96(13), 7532-7537 (1999)

34. Chiavegatto, S., Sun, J., Nelson, R.J., Schnaar, R.L.: A functional role for complex gangliosides: motor deficits in GM2/GD2 synthase knockout mice. Exp Neurol 166(2), 227-234 (2000). doi:10.1006/ exnr.2000.7504

35. Yin, X., Crawford, T.O., Griffin, J.W., Tu, P., Lee, V.M., Li, C., Roder, J., Trapp, B.D.: Myelin-associated glycoprotein is a myelin signal that modulates the caliber of myelinated axons. J Neurosci Off J Soc Neurosci 18(6), 1953-1962 (1998)

36. Sha, S., Zhou, L., Yin, J., Takamiya, K., Furukawa, K., Sokabe, M., Chen, L.: Deficits in cognitive function and hippocampal plasticity in GM2/GD2 synthase knockout mice. Hippocampus 24(4), 369-382 (2014)

37. Takamiya, K., Yamamoto, A., Furukawa, K., Zhao, J., Fukumoto, S., Yamashiro, S., Okada, M., Haraguchi, M., Shin, M., Kishikawa, M., Shiku, H., Aizawa, S.: Complex gangliosides are essential in spermatogenesis of mice: possible roles in the transport of testosterone. Proc Natl Acad Sci U S A 95(21), 12147-12152 (1998)

38. Sandhoff, R., Geyer, R., Jennemann, R., Paret, C., Kiss, E., Yamashita, T., Gorgas, K., Sijmonsma, T.P., Iwamori, M., Finaz, C., Proia, R.L., Wiegandt, H., Grone, H.J.: Novel class of glycosphingolipids involved in male fertility. J Biol Chem 280(29), 27310-27318 (2005). doi:10.1074/jbc.M502775200

39. Yamashita, T., Hashiramoto, A., Haluzik, M., Mizukami, H., Beck, S., Norton, A., Kono, M., Tsuji, S., Daniotti, J.L., Werth, N., Sandhoff, R., Sandhoff, K., Proia, R.L.: Enhanced insulin sensitivity in mice lacking ganglioside GM3. Proc Natl Acad Sci U S A 100(6), 3445-3449 (2003). doi:10.1073/pnas.0635898100

40. Wang, X.Q., Lee, S., Wilson, H., Seeger, M., Iordanov, H., Gatla, N., Whittington, A., Bach, D., Lu, J.Y., Paller, A.S.: Ganglioside GM3 depletion reverses impaired wound healing in diabetic mice by activating IGF-1 and insulin receptors. J Invest Dermatol 134(5), 14461455 (2014). doi:10.1038/jid.2013.532

41. Yoshikawa, M., Go, S., Takasaki, K., Kakazu, Y., Ohashi, M., Nagafuku, M., Kabayama, K., Sekimoto, J., Suzuki, S., Takaiwa, K., Kimitsuki, T., Matsumoto, N., Komune, S., Kamei, D., Saito, M., Fujiwara, M., Iwasaki, K., Inokuchi, J.: Mice lacking ganglioside GM3 synthase exhibit complete hearing loss due to selective degeneration of the organ of Corti. Proc Natl Acad Sci U S A 106(23), 9483-9488 (2009). doi:10.1073/pnas.0903279106

42. Okada, M., Itoh Mi, M., Haraguchi, M., Okajima, T., Inoue, M., Oishi, H., Matsuda, Y., Iwamoto, T., Kawano, T., Fukumoto, S., Miyazaki, H., Furukawa, K., Aizawa, S.: b-series Ganglioside deficiency exhibits no definite changes in the neurogenesis and the sensitivity to Fas-mediated apoptosis but impairs regeneration of the lesioned hypoglossal nerve. J Biol Chem 277(3), 1633-1636 (2002). doi:10.1074/jbc.C100395200 
43. Kawai, H., Allende, M.L., Wada, R., Kono, M., Sango, K., Deng, C., Miyakawa, T., Crawley, J.N., Werth, N., Bierfreund, U., Sandhoff, K., Proia, R.L.: Mice expressing only monosialoganglioside GM3 exhibit lethal audiogenic seizures. J Biol Chem 276(10), 6885-6888 (2001). doi:10.1074/jbc.C000847200

44. Handa, Y., Ozaki, N., Honda, T., Furukawa, K., Tomita, Y., Inoue, M., Okada, M., Sugiura, Y.: GD3 synthase gene knockout mice exhibit thermal hyperalgesia and mechanical allodynia but decreased response to formalin-induced prolonged noxious stimulation. Pain 117(3), 271-279 (2005). doi:10.1016/j.pain.2005.06.016

45. Tajima, O., Egashira, N., Ohmi, Y., Fukue, Y., Mishima, K., Iwasaki, K., Fujiwara, M., Inokuchi, J., Sugiura, Y., Furukawa, $\mathrm{K}$.: Reduced motor and sensory functions and emotional response in GM3-only mice: emergence from early stage of life and exacerbation with aging. Behav Brain Res 198(1), 74-82 (2009). doi:10. 1016/j.bbr.2008.10.024

46. Inoue, M., Fujii, Y., Furukawa, K., Okada, M., Okumura, K., Hayakawa, T., Sugiura, Y.: Refractory skin injury in complex knock-out mice expressing only the GM3 ganglioside. J Biol Chem 277(33), 29881-29888 (2002). doi:10.1074/jbc.M201631200

47. Yamashita, T., Wu, Y.P., Sandhoff, R., Werth, N., Mizukami, H., Ellis, J.M., Dupree, J.L., Geyer, R., Sandhoff, K., Proia, R.L.: Interruption of ganglioside synthesis produces central nervous system degeneration and altered axon-glial interactions. Proc Natl Acad Sci U S A 102(8), 2725-2730 (2005). doi:10.1073/pnas.0407785102

48. Okuda, T., Tokuda, N., Numata, S., Ito, M., Ohta, M., Kawamura, K., Wiels, J., Urano, T., Tajima, O., Furukawa, K.: Targeted disruption of Gb3/CD77 synthase gene resulted in the complete deletion of globoseries glycosphingolipids and loss of sensitivity to verotoxins. J Biol Chem 281(15), 10230-10235 (2006). doi:10.1074/jbc.M600057200

49. Porubsky, S., Speak, A.O., Luckow, B., Cerundolo, V., Platt, F.M., Grone, H.J.: Normal development and function of invariant natural killer $\mathrm{T}$ cells in mice with isoglobotrihexosylceramide (iGb3) deficiency. Proc Natl Acad Sci U S A 104(14), 5977-5982 (2007). doi: 10.1073/pnas.0611139104

50. Zhou, D., Mattner, J., Cantu 3rd, C., Schrantz, N., Yin, N., Gao, Y., Sagiv, Y., Hudspeth, K., Wu, Y.P., Yamashita, T., Teneberg, S., Wang, D., Proia, R.L., Levery, S.B., Savage, P.B., Teyton, L., Bendelac, A.: Lysosomal glycosphingolipid recognition by NKT cells. Science 306(5702), 1786-1789 (2004). doi:10.1126/science.1103440

51. Biellmann, F., Hulsmeier, A.J., Zhou, D., Cinelli, P., Hennet, T.: The Lc3-synthase gene B3gnt5 is essential to pre-implantation development of the murine embryo. BMC Dev Biol 8, 109 (2008). doi:10. 1186/1471-213X-8-109

52. Togayachi, A., Kozono, Y., Ikehara, Y., Ito, H., Suzuki, N., Tsunoda, Y., Abe, S., Sato, T., Nakamura, K., Suzuki, M., Goda, H.M., Ito, M., Kudo, T., Takahashi, S., Narimatsu, H.: Lack of lacto/neolactoglycolipids enhances the formation of glycolipid-enriched microdomains, facilitating B cell activation. Proc Natl Acad Sci U S A 107(26), 11900-11905 (2010). doi:10.1073/pnas.0914298107

53. Kuan, C.T., Chang, J., Mansson, J.E., Li, J., Pegram, C., Fredman, P., McLendon, R.E., Bigner, D.D.: Multiple phenotypic changes in mice after knockout of the B3gnt5 gene, encoding Lc3 synthase-a key enzyme in lacto-neolacto ganglioside synthesis. BMC Dev Biol 10, 114 (2010). doi:10.1186/1471-213X-10-114

54. Schulte, S., Stoffel, W.: Ceramide UDPgalactosyltransferase from myelinating rat brain: purification, cloning, and expression. Proc Natl Acad Sci U S A 90(21), 10265-10269 (1993)

55. Coetzee, T., Fujita, N., Dupree, J., Shi, R., Blight, A., Suzuki, K., Popko, B.: Myelination in the absence of galactocerebroside and sulfatide: normal structure with abnormal function and regional instability. Cell 86(2), 209-219 (1996)

56. Bosio, A., Binczek, E., Stoffel, W.: Functional breakdown of the lipid bilayer of the myelin membrane in central and peripheral nervous system by disrupted galactocerebroside synthesis. Proc Natl Acad Sci U S A 93(23), 13280-13285 (1996)
57. Zoller, I., Bussow, H., Gieselmann, V., Eckhardt, M.: Oligodendrocyte-specific ceramide galactosyltransferase (CGT) expression phenotypically rescues CGT-deficient mice and demonstrates that CGT activity does not limit brain galactosylceramide level. Glia 52(3), 190-198 (2005). doi:10.1002/glia.20230

58. Hirahara, Y., Tsuda, M., Wada, Y., Honke, K.: cDNA cloning, genomic cloning, and tissue-specific regulation of mouse cerebroside sulfotransferase. Eur J Biochem FEBS 267(7), 1909-1917 (2000)

59. Eckhardt, M.: The role and metabolism of sulfatide in the nervous system. Mol Neurobiol 37(2-3), 93-103 (2008). doi:10.1007/ s12035-008-8022-3

60. Takahashi, T., Suzuki, T.: Role of sulfatide in normal and pathological cells and tissues. J Lipid Res 53(8), 1437-1450 (2012). doi:10. 1194/jlr.R026682

61. Ishizuka, I.: Chemistry and functional distribution of sulfoglycolipids. Prog Lipid Res 36(4), 245-319 (1997)

62. Honke, K., Hirahara, Y., Dupree, J., Suzuki, K., Popko, B., Fukushima, K., Fukushima, J., Nagasawa, T., Yoshida, N., Wada, Y., Taniguchi, N.: Paranodal junction formation and spermatogenesis require sulfoglycolipids. Proc Natl Acad Sci U S A 99(7), 42274232 (2002). doi:10.1073/pnas.032068299

63. Hoshi, T., Suzuki, A., Hayashi, S., Tohyama, K., Hayashi, A., Yamaguchi, Y., Takeuchi, K., Baba, H.: Nodal protrusions, increased Schmidt-Lanterman incisures, and paranodal disorganization are characteristic features of sulfatide-deficient peripheral nerves. Glia 55(6), 584-594 (2007). doi:10.1002/glia.20487

64. Ishibashi, T., Dupree, J.L., Ikenaka, K., Hirahara, Y., Honke, K., Peles, E., Popko, B., Suzuki, K., Nishino, H., Baba, H.: A myelin galactolipid, sulfatide, is essential for maintenance of ion channels on myelinated axon but not essential for initial cluster formation. $\mathrm{J}$ Neurosci Off J Soc Neurosci 22(15), 6507-6514 (2002)

65. Hayashi, A., Kaneko, N., Tomihira, C., Baba, H.: Sulfatide decrease in myelin influences formation of the paranodal axo-glial junction and conduction velocity in the sciatic nerve. Glia 61(4), 466-474 (2013). doi:10.1002/glia.22447

66. Lullmann-Rauch, R., Matzner, U., Franken, S., Hartmann, D., Gieselmann, V.: Lysosomal sulfoglycolipid storage in the kidneys of mice deficient for arylsulfatase A (ASA) and of double-knockout mice deficient for ASA and galactosylceramide synthase. Histochem Cell Biol 116(2), 161-169 (2001). doi:10.1007/s004180100286

67. Sandhoff, R., Hepbildikler, S.T., Jennemann, R., Geyer, R., Gieselmann, V., Proia, R.L., Wiegandt, H., Grone, H.J.: Kidney sulfatides in mouse models of inherited glycosphingolipid disorders: determination by nano-electrospray ionization tandem mass spectrometry. J Biol Chem 277(23), 20386-20398 (2002). doi:10.1074/ jbc.M110641200

68. Stettner, P., Bourgeois, S., Marsching, C., Traykova-Brauch, M., Porubsky, S., Nordstrom, V., Hopf, C., Koesters, R., Sandhoff, R., Wiegandt, H., Wagner, C.A., Grone, H.J., Jennemann, R.: Sulfatides are required for renal adaptation to chronic metabolic acidosis. Proc Natl Acad Sci U S A 110(24), 9998-10003 (2013). doi:10.1073/pnas. 1217775110

69. Schulze, H., Sandhoff, K.: Sphingolipids and lysosomal pathologies. Biochim Biophys Acta 1841(5), 799-810 (2014). doi:10.1016/j. bbalip.2013.10.015

70. Farukhi, F., Dakkouri, C., Wang, H., Wiztnitzer, M., Traboulsi, E.I.: Etiology of vision loss in ganglioside GM3 synthase deficiency. Ophthalmic Genet 27(3), 89-91 (2006). doi:10.1080/ 13816810600862626

71. Wang, H., Bright, A., Xin, B., Bockoven, J.R., Paller, A.S.: Cutaneous dyspigmentation in patients with ganglioside GM3 synthase deficiency. Am J Med Genet A 161A(4), 875-879 (2013). doi: 10.1002/ajmg.a.35826

72. Simpson, M.A., Cross, H., Proukakis, C., Priestman, D.A., Neville, D.C., Reinkensmeier, G., Wang, H., Wiznitzer, M., Gurtz, K., Verganelaki, A., Pryde, A., Patton, M.A., Dwek, R.A., Butters, 
T.D., Platt, F.M., Crosby, A.H.: Infantile-onset symptomatic epilepsy syndrome caused by a homozygous loss-of-function mutation of GM3 synthase. Nat Genet 36(11), 1225-1229 (2004). doi:10.1038/ ng1460

73. Harlalka, G.V., Lehman, A., Chioza, B., Baple, E.L., Maroofian, R., Cross, H., Sreekantan-Nair, A., Priestman, D.A., Al-Turki, S., McEntagart, M.E., Proukakis, C., Royle, L., Kozak, R.P., Bastaki, L., Patton, M., Wagner, K., Coblentz, R., Price, J., Mezei, M., Schlade-Bartusiak, K., Platt, F.M., Hurles, M.E., Crosby, A.H.: Mutations in B4GALNT1 (GM2 synthase) underlie a new disorder of ganglioside biosynthesis. Brain J Neurol 136(Pt 12), 3618-3624 (2013). doi:10.1093/brain/awt270

74. Natoli, T.A., Husson, H., Rogers, K.A., Smith, L.A., Wang, B., Budman, Y., Bukanov, N.O., Ledbetter, S.R., Klinger, K.W., Leonard, J.P., Ibraghimov-Beskrovnaya, O.: Loss of
GM3 synthase gene, but not sphingosine kinase 1, is protective against murine nephronophthisis-related polycystic kidney disease. Hum Mol Genet 21(15), 3397-3407 (2012). doi:10. 1093/hmg/dds 172

75. Natoli, T.A., Smith, L.A., Rogers, K.A., Wang, B., Komarnitsky, S., Budman, Y., Belenky, A., Bukanov, N.O., Dackowski, W.R., Husson, H., Russo, R.J., Shayman, J.A., Ledbetter, S.R., Leonard, J.P., Ibraghimov-Beskrovnaya, O.: Inhibition of glucosylceramide accumulation results in effective blockade of polycystic kidney disease in mouse models. Nat Med 16(7), 788-792 (2010). doi:10.1038/ nm. 2171

76. McDonald, G., Deepak, S., Miguel, L., Hall, C.J., Isenberg, D.A., Magee, A.I., Butters, T., Jury, E.C.: Normalizing glycosphingolipids restores function in $\mathrm{CD} 4+\mathrm{T}$ cells from lupus patients. J Clin Invest 124(2), 712-724 (2014). doi:10.1172/JCI69571 